\title{
Extraterritorial Laws for Cross-Border Reproductive Care: The Issue of Legal Diversity
}

\author{
Wannes Van Hoof and Guido Pennings \\ Bioethics Institute Ghent, Blandijnberg 2, B-9000 Ghent, Belgium
}

\begin{abstract}
Certain states impose restrictions on assisted reproduction because they believe such acts to be morally wrong. However, people who live in a state with restrictive legislation always have the option of going abroad to evade that law. Turkey and several states in Australia have enacted extraterritorial laws to stop forms of reproductive travelling for law evasion. Within the EU, the European Convention of Human Rights would normally remove the need for extraterritorial laws. However, because of the wide margin of appreciation allowed by the European Court of Human Rights, legal diversity on these matters persists. In the case of S.H. and Others v. Austria, moral justification, consistency and proportionality were introduced by the First Section to rule on Member States' legislation on medically assisted reproduction. The First Section mostly ruled on the effectiveness of the law, while the focus should be on the validity of the normative aim. The Grand Chamber reversed this judgement based on the margin of appreciation doctrine, using it as a pragmatic substitute for a substantial decision. In general, the EU's interests of harmonization and unification are at odds with the right to national identity of individual states in areas of contested morality.
\end{abstract}

\section{Keywords}

cross-border reproductive care (CBRC); margin of appreciation; extraterritoriality; proportionality; medically-assisted reproduction; moral justification; reproductive tourism; legal pluralism

\section{Introduction}

Cross-border reproductive care (CBRC) is a growing phenomenon where infertile patients cross borders in order to obtain reproductive treatment abroad. In a recent survey it was estimated that within Europe at least 24000-30000 cycles are performed annually on at least 11000-14000 foreign patients. ${ }^{1}$ The different causes of CBRC can be divided into two groups: legal restrictions and/or availability issues in the state of affiliation. ${ }^{2}$ This is not surprising, since patients are less likely to travel if the treatment they need is readily available at home. The

1) F. Shenfield, J. de Mouzon, G. Pennings, A.P. Ferraretti, A. Nyboe Andersen, G. de Wert and V. Goossens, "Cross-border reproductive care in six European countries", Human Reproduction 25(6) (2010) 1361-1368.

2) G. Pennings, G. de Wert, F. Shenfield, J. Cohen, B. Tarlatzis and P. Devroey, "ESHRE Task Force on Ethics and Law 15: Cross-Border Reproductive Care", Human Reproduction 23(10) (2008) 2182-2184. 
survey showed that most patients $(54.8 \%)$ travelled for legal reasons. ${ }^{3}$ We will focus on those patients who cross borders to circumvent the law in their state of affiliation because they pose some interesting legal and moral questions.

In an earlier article, we approached the issue of CBRC for law evasion from the perspective of the individual and the state. ${ }^{4}$ In this text, we consider the issue from a European perspective: How can the EU balance different national identities in morally sensitive areas on the one hand and free movement laws on the other? How can a Member State that imposes restrictions on certain forms of assisted reproduction protect its moral position when its citizens can travel freely to other Member States for the treatment?

\section{Legal Diversity}

The issue with legal diversity is that some countries prohibit some forms of medically assisted reproduction (e.g., oocyte donation) or deny access to some groups of people (e.g., same sex couples) while other countries permit the same actions. The lack of consensus is also striking among the EU Member States. If one were to take a biopsy of the legal situation in one country in Europe, one would know nothing about the legal situation in the neighbouring countries or about European legislation as a whole. ${ }^{5}$ The laws on gamete donation perfectly illustrate legal diversity within Europe. Italy, Lithuania and Turkey prohibit gamete donation completely. All other states allow sperm donation and sperm donors are usually given a small compensation (approximately 50-100 Euros). Austria, Croatia, Germany, Norway and Switzerland ban egg donation. The Czech Republic and Spain allow egg donation and payments to egg donors of 800 and 900 Euros, respectively. In several states, including Cyprus and Romania, the matter is not regulated, but gamete donation is used in practice. On the matter of identifiability of the donor, the whole spectrum of possibilities is present, ranging from compulsory anonymity (e.g., France, Spain and Norway) over double track systems (e.g., Iceland) to complete identifiability (e.g., The Netherlands, the UK and Sweden).

Legal diversity is a necessary condition for the worldwide phenomenon where patients are travelling abroad to wherever the treatment they are looking for is provided. Within the EU patients may even be entitled to reimbursement for (part of) such treatment in some cases. For example, when a Dutch couple goes to Belgium to use an anonymous sperm donor because the Dutch law only allows

\footnotetext{
3) Supra note 1.

4) W. Van Hoof and G. Pennings, "Extraterritoriality for cross-border reproductive care: should states act against citizens travelling abroad for illegal infertility treatment?", Reproductive Biomedicine Online 23 (2011) 546-554.

5) G. Pennings, "International evolution of legislation and guidelines in medically assisted reproduction", Reproductive Biomedicine Online 18 supplement 2 (2009) 15-18.
} 
identifiable donation, the treatment will be reimbursed as if it had taken place in the Netherlands.

Several patterns have developed over the years directly affected by legal developments. For instance, in France, only heterosexual couples have access to fertility treatments, so many French lesbians travel to Belgium to be inseminated with donor sperm. ${ }^{6}$ After the restrictive Italian law was enacted in 2004, 'reproductive emigration' quadrupled (from 1066 in 2003, to 4173 in 2005). ${ }^{7}$ The permissive policies on egg donation in Spain and the Czech Republic have made them popular destinations for couples that require donor eggs. Many Italians go to Spain and many Germans to the Czech Republic to evade restrictions on egg donation in their home state. ${ }^{8}$

\section{Extraterritorial Laws}

\subsection{Extraterritorial Laws in Areas of Legal Diversity}

People who live in a state with restrictive legislation always have the option of going abroad to evade that law. However, the reason why certain states impose restrictions on medically assisted reproduction is because they believe such acts to be morally wrong. The act of crossing a border does not change the morality of an act fundamentally: if an act is wrong, it is wrong wherever it takes place. From an ethical point of view, extraterritoriality would be the rule.

In the past, states rarely reacted to their citizens going abroad for fertility treatment that is illegal at home. Maybe such movements went unnoticed, maybe they were tolerated or maybe they believed that they simply could not do anything to stop them. Recently, however, Turkey and several states in Australia have enacted extraterritorial laws that are directly aimed at putting an end to reproductive travelling.

Turkey has justified strict prohibitions on gamete donation and surrogacy, including treatments abroad by referring to item 231 of the Turkish Penal Code, according to which it is illegal to "change or obscure a child's ancestry". If it is discovered that an individual has travelled abroad to receive fertility treatment using donor eggs, donor sperm or surrogacy, then the person who has conducted this procedure, the persons who have referred patients or acted as intermediaries,

6) G. Pennings, "Cross-border reproductive care in Belgium", Human Reproduction 24(12) (2009) 3108-3118.

7) A.P. Ferraretti, G. Pennings, L. Gianaroli, F. Natali and M.C. Magli, "Cross-border reproductive care: a phenomenon expressing the controversial aspects of reproductive technologies", Reproductive Biomedicine Online 20 (2010), 261-266.

8) Supra note 1. 
the impregnated person, and the donor will be reported to the state prosecutor. ${ }^{9}$ They are all potentially subject to punishment of one to three years imprisonment. The recent 'Surrogacy Bill 2010' in New South Wales (NSW), Australia, includes punishments for those who enter into commercial arrangements of up to two years in jail, a fine of $\$ 110,000$ or both. The law was given an extraterritorial scope to cement the government's position on commercial surrogacy in the best interest of the child, to close a loophole in the proposed bill and to prevent exploitation of vulnerable women. ${ }^{10}$

These laws grant the state power of prosecution based on the nationality of the actor. The nationality principle offers a powerful legal tool to impose a universal duty to obey the law. However, there are serious philosophical issues with this principle: the ground for a state's right to punish is territorial in nature and it is in the best interest of both residents and non-residents on a territory to be under local legal protection. ${ }^{11}$ In areas of contested morality, there are judicial issues with extraterritoriality regarding choice of law and the question of double criminality. ${ }^{12}$ Double criminality means that people can only be punished for extraterritorial actions that are considered a crime in both countries. In areas of legal diversity, double criminality renders extraterritorial laws meaningless. Even when it seems that there is a widespread legal consensus, as is the case for sex with children, double criminality may prove to be an impediment, as ages of consent may still differ across cultures. ${ }^{13}$ If states accept no exceptions to the age of consent for cultural or other reasons, double criminality components must be removed from sex tourism legislation. Without double criminality extraterritorial laws imply moral radicalism, which is only justified for acts that are clearly harmful or wrong. In legal terms, this means that extraterritoriality is only justified when there is a human rights violation.

\subsection{The Moral Grounds for Extraterritoriality}

There are three instances of extraterritorial laws based on the nationality principle in domains that share characteristics with certain applications of medically assisted reproduction: abortion, sex with children and female genital cutting (FGC). These domains pertain to respect for the embryo and foetus, rights of the child and women's rights. Analogical reasoning based on the formal principle of justice

\footnotetext{
9) Z.B. Gürtin, "Banning reproductive travel: Turkey's ART legislation and third-party assisted reproduction", Reproductive Biomedicine Online 23 (2011) 555-564.

10) NSW Parliament, 11/11/2010. "Surrogacy Bill 2010.” Retrieved 26 August 2011, www.parliament. nsw.gov.au/prod/parlment/hansart.nsf/V3Key/LC20101111047.

11) A. Chehtman, "The Extraterritorial Scope of the Right to Punish", Law and Philosophy 29 (2010) 127-157.

12) J.W. Dellapenna, "Abortion across state lines", Brigham Young University Law Review (2008) 1651-1702.

13) A. Fraley, "Child Sex Tourism Legislation under the Protect Act: Does It Really Protect?", St. Johns Law Review 79 (2005) 445-484.
} 
(similar cases must be treated similarly and different cases differently) will bring forward the moral grounds for extraterritorial laws in general and in the case of assisted reproduction. ${ }^{14}$ These analogies will clarify what constitutes a reasonable and objective justification to recognize an act as a 'clear moral wrong'.

There are two general lines of reasoning to justify an act or decision: utilitarian arguments that refer to the effects on the welfare of the persons involved and deontological arguments that refer to moral rules, moral principles and rights and duties. These arguments partly overlap: interests of people are protected by rights, but in some cases a person's rights can be violated even if the person is better off (or at least not worse off) after the violation. In the case of sex with children, a review of the available empirical evidence showed that this does not harm them significantly over time, especially if the sexual experience was nonviolent and consensual. ${ }^{15}$ However, a strict ban on sex with children is still justified based on the right of a child to sexual autonomy and bodily integrity.

In the case of FGC, there is a lot of international lobbying, most notably from the WHO, to universally condemn the practice. This resulted in an extensive legal consensus. Several European countries reacted to this international pressure by implementing specific legislation (e.g., Austria in 2002, Belgium in 2001, Denmark in 2003, Italy in 2005, Spain in 2003, Sweden in 1982, the UK in 2004), or by making general law provisions applicable to FGC. ${ }^{16}$ Deontological arguments for this condemnation are based on several rights, including the protection of bodily integrity and protection against discrimination. ${ }^{17}$ Utilitarian arguments are straightforward: mutilating a woman's genitals is clearly harmful. Because the extensive forms of FGC constitute an indisputable moral wrong, extraterritorial laws without double criminality can be justified. However, even though the WHO identifies four different types of FGC, they all fall under the general condemnation. There are forms of symbolic cutting in a medical setting that are not significantly harmful. ${ }^{18}$ For these minimal invasive forms of cutting, the right to cultural identity and expression can be asserted.

It is not always easy to discern what a 'clear moral wrong' is. For abortion, a very strong consistent case can be made to justify a restrictive policy. If one attributes a high moral status to the embryo and foetus, abortion constitutes some kind of murder. It would be inconsistent with such conviction to allow citizens to

\footnotetext{
14) Supra note 4.

15) B. Rind, P. Tromovitch and R. Bauserman, "A meta-analytic examination of assumed properties of child sexual abuse using college samples", Psychological Bulletin 124(1) (1998) 22-53.

16) E. Leye, J. Deblonde, J. García-Añón, S. Johnsdotter, A. Kwateng-Kluvitse, L. Weil-Curiel and M. Temmerman, "An analysis of the implementation of laws with regard to female genital mutilation in Europe", Crime Law Sociological Change 47 (2007) 1-31.

17) WHO, 2008, "Eliminating female genital mutilation: an interagency statement." Retrieved 26 August 2011, http://www.who.int/reproductivehealth/publications/fgm/9789241596442/en/index.html.

18) A.E. Galeotti, "Relativism, universalism, and applied ethics: the case of female circumcision", Constellations 14 (2007) 91-111.
} 
terminate their pregnancies abroad. Take the Irish abortion policy for example. In Ireland, any abortion is illegal unless the pregnancy endangers the life of the woman. This is a consistent policy: if the embryo or foetus is a human life, only another human life can outbalance its right to life. In the landmark case of Attorney General v. $X$, the Republic of Ireland did try to deny a 14 year old rape victim the right to travel because she was going to terminate her pregnancy. A series of judgements by the European Courts subsequently confirmed that restricting travel is a direct violation of the European Community treaty, which guarantees free movement of persons and services. For a short while during the early 90 s, gynaecological examinations were forced on some women returning from the Netherlands at the German border. These women were criminally prosecuted if they had had an abortion. However, this practice was condemned by the European Parliament on the grounds that "the internal borders of the [European] Community may not be used to threaten citizens with prosecution for activities that are perfectly legal in some Member States but not in others" ${ }^{19}$ Because of legal diversity and EU laws on free movement, the Irish government has to allow its citizens to go abroad to commit 'murder'. The UK Department of Health publishes annual numbers estimating that between January 1980 and December 2010, at least 146,442 women travelled from the Republic of Ireland for abortion services in the UK. ${ }^{20}$

The central question in all this is what the difference is between sex with children and extensive FGC on the one hand, and abortion on the other hand. In both cases, the act in question is considered a clear moral wrong in an individual Member State. There is no reaction from the EU to extraterritorial laws that prohibit travelling for sex with children or FGC. For abortion, however, European law dictates that states should grant their nationals the right to travel. It is not the individual Member State's appreciation of the seriousness of the act that determines whether or not extraterritoriality is warranted. When Europe agrees with the prohibition, exterritorial laws are accepted; if Europe disagrees, they are forbidden.

\subsection{The Morality of Extraterritorial Laws for CBRC}

Most treatments for which people cross borders in the case of CBRC for law evasion are not necessarily morally wrong. The only treatment that is universally recognized as harmful or wrong at the moment is reproductive cloning. For all other treatments the harm or the fundamental right that forms the ground for

\footnotetext{
19) Resolution on Compulsory Gynaecological Examinations at the Dutch-German Border of March 14, 1991, 1991 OJ. (C 106) 113.

20) IFPA. 2011. "Between January 1980 and December 2010, at least 147,912 women travelled from the Republic of Ireland for safe abortion services abroad." Retrieved 26 August 2011 http://www.ifpa.ie/ Hot-Topics/Abortion/Statistics.
} 
legislation is avoidable or disputable, so the application of the nationality principle would be too radical. ${ }^{21}$ There is a lack of justification for the Turkish and NSW extraterritorial laws because gamete donation and commercial surrogacy are not indisputable moral wrongs.

In the case of commercial surrogacy, restrictive legislation may result in a factual extraterritorial ban, as a side effect of national laws. There have been court cases in several states including Belgium, France, Germany and the UK because the commissioning couple could not bring their offspring home after an international commercial surrogacy arrangement. The surrogacy contract that recognizes the commissioning couple as legal parents is not recognized in states that prohibit commercial surrogacy or have no legislation on the matter. In this situation, the state of treatment (e.g., India, Ukraine, US) recognizes the commissioning couple as legal parents and the couple's home state considers the birth mother, i.e. the surrogate as legal parent. As a consequence, the children are stuck abroad, in between two legal systems, waiting for a court decision that calls for an exception to the law 'in the best interest of the child'. ${ }^{22}$

If extraterritoriality for commercial surrogacy is unjustified, should states not address such issues of comity as well? Until now, these court decisions are not recognized as precedents, which means that similar cases will continue to emerge. If they would become precedents, foreign commercial surrogacy contracts would become valid in restrictive states. In practice, this would mean that states should actively make possible behaviour of their citizens that they consider immoral. In a way, this is what current EU legislation and case law demand of Member States with regard to treatments that are legal in some states but not in others, such as abortion, anonymous or identifiable gamete donation, preimplantation genetic diagnosis and the like.

\section{Consistencies and Inconsistencies at EU Level}

\subsection{Tensions in EU Legislation}

Health policy in the EU has a fundamental tension at its core. On the one hand, article 168(7) of the EC Treaty states explicitly that public health is the responsibility of the Member States. On the other hand, many aspects of national health care systems are subject to EU law and policy because health care involves people (e.g., medical staff and patients), goods (e.g., drugs and devices) and services (health care funders and providers), all of which are granted freedom of movement across borders. The effect of EU laws on health care form a kind of patchwork,

\footnotetext{
21) Supra note 4.

22) E.g. A.J. et F.V. 22/03/2010, tribunal of Huy, Journal des Tribunaux 2010, 420.
} 
unconnected by legal or policy coherence. ${ }^{23}$ The recent directive on the application of patients' rights in cross-border healthcare $(2011 / 24 / \mathrm{EU})$ is one small step in the direction of legal harmonization on the basics of cross-border healthcare, but it does not alleviate the tension of legal diversity on ethically controversial treatments. A Member State cannot prevent its citizens from going abroad to get fertility treatment that it considers illegal and immoral. The discussions on the European directive on patient mobility show that there were some real concerns that the rights given to the patients to obtain treatment abroad would imply that Member States would be obliged to pay for illegal treatment. Therefore, an amendment was introduced to make it clear that the directive does not imply that Member States would have to reimburse "ethically controversial medical 'services' like euthanasia, DNA-testing or IVF" when the relevant service is not allowed, or at least not financed, in the relevant Member States. ${ }^{24}$ The Member States wanted to keep their autonomy to decide which treatments are ethically acceptable. The directive ensures that Member States can still decide which treatments to reimburse and explicitly states that "no provision of this Directive should be interpreted in such a way as to undermine the fundamental ethical choices of Member States." 25

The argument can also be approached the other way around: it is in principle possible that EU citizens claim before the ECJ that the Irish abortion ban restrains them from making use of their free movement rights. ${ }^{26}$ This would only be possible if the ECtHR judgement in Tysiac v. Poland implies that EU law guarantees a right to therapeutic abortion. ${ }^{27}$ Otherwise the Irish government could argue that they do not deter people from travelling for an abortion.

The European Convention of Human Rights (ECHR) is the alfa and omega to evaluate legislation in areas of contested morality in Member States. The ECtHR developed the concept of 'margin of appreciation' to take into account that the principles of the Convention are broadly-drawn and to anticipate variable interpretations in different societies. In principle, this doctrine limits the tension between the EU's twofold objective to respect national identities of the Member States in moral issues and to maximize free movement without restrictions. No

23) T. Hervey and B. Vanhercke, "Health care and the EU: the law and policy patchwork", in: E. Mossialos, G. Permanand, R. Baeten and T. Hervey (eds.) Health Systems Governance in Europe: The Role of European Union Law and Policy (Cambridge: Cambridge University Press, 2010) pp. 84-133.

24) European Parliament, 2009. Report on the proposal for a directive of the European Parliament and of the Council on the application of patients' rights in cross-border healthcare $(\operatorname{COM}(2008) 0414$ C6-0257/2008 - 2008/0142(COD)) Committee on the Environment, Public Health and Food Safety.

25) Directive 2011/24/EU of the European Parliament and of the Council of 9 March 2011 on the application of patients' rights in cross-border healthcare, recitals 33 and 7.

26) N. Koffeman, "The impact of EU fundamental freedoms on diverging human rights standards; a need for (European) regulation?" Paper for the Dubrovnik seminar on Market Freedoms and Fundamental Rights in the Enlarging European Union (2010).

27) N. Priaulx, "Testing the Margin of Appreciation: Therapeutic Abortion, Reproductive 'Rights' and the Intriguing Case of Tysiąc v. Poland", European Journal of Health Law 15 (2008) 361-379. 
state should try to prevent its citizens from going abroad to circumvent the law because all states adhere to a certain appreciation of the ECHR. However, for some of the most sensitive issues within the EU, like abortion and assisted reproduction, the ECtHR holds that 'the margin of appreciation afforded to the respondent state must be a wide one' ${ }^{28}$ In practice, this means that the ECtHR names both restrictive policies (Lithuania, Italy and Turkey) and permissive policies on gamete donation as valid appreciations. ${ }^{29}$ It means that the court has limited powers when some states deny rights, such as the right to abortion, that almost all other Member States consider valid. ${ }^{30}$ From the point of view of the restrictive state, this means that they are forced to allow their citizens to go abroad to commit immoral acts. The margin of appreciation does not solve issues of legal diversity in areas of contested morality when it is very wide.

\subsection{The Demand for Consistency and Justification in the First Section Judgement of S.H. and Others $v$. Austria}

The margin of appreciation doctrine results in a confirmation of legal diversity. In areas of contested morality, a different concept is used to rule on legislation: proportionality. Proportionality requires that restrictive policies are rationally related to their final aim. Because human reproduction is so fundamental to human experience and because medically assisted reproduction is subject to diametrically opposed moral reactions, the standard is raised to a heightened level of rationality or proportionality. ${ }^{31}$ Because of the private nature of procreative choice and the fundamental rights at stake, "the least intrusive means of achieving the aim pursued" are preferable. ${ }^{32}$ In short, states should enact the least intrusive legislation that expresses a legitimate moral position conform the national identity and beliefs.

The concept of proportionality amounts to another means for the ECtHR to limit the interpretations of the ECHR besides the margin of appreciation. It serves to prevent restrictions that have little to do with the achievement of the normative goal. In S.H. and Others v. Austria, the 1992 Artificial Procreation Act, which prohibits egg donation entirely and sperm donation for the purpose of IVF, was deemed disproportionate by the First Section. Austria's justification for this policy was that use of third party gametes could lead to 'selection' of children, that there is a risk of exploitation and humiliation of egg donors, that allowing gamete donation would lead to unusual (/unnatural) relationships and that

\footnotetext{
28) European Commission of Human Rights Hercz v. Norway appl. No. 17004/90, 1992; ECtHR Grand Chamber S.H. and Others v. Austria appl. No. 57813/00, 2011.

29) ECtHR S.H. and Others v. Austria appl. No. 57813/00, 2010-2011.

30) ECtHR A.B. and C. v. Ireland appl. No. 25579/05, 2010.

31) R. Storrow, "The pluralism problem in cross-border reproductive care", Human Reproduction 25(12) (2010) 2939-2943.

32) ECtHR First Section S.H. and Others v. Austria appl. No. 57813/00, 2010.
} 
children have a right to be informed about their genetic origins. The German government, which enacted very similar legislation, also submitted to the court that allowing egg donation would split motherhood in two, which 'would be an absolute novelty in nature and in the history of mankind'. It would interfere with the basic principle mater semper certa est.

The first and second applicants in S.H. and Others v. Austria could only conceive a child by making use of donor sperm and IVF, while the third and fourth applicants needed egg donation. They argued that their right to respect for private and family life (ECHR Article 8) was violated and that the incoherence in allowing some techniques but not others amounted to unjustified discrimination (ECHR Article 14). The First Section held that the Austrian government provided insufficient justification to treat people who need to fulfil their wish for a child using gamete donation differently. Social acceptability is not a sufficient reason for a complete ban of a specific procreation technique. Moreover, unusual family relationships are nothing new in modern families. As far as the risk of exploitation of egg donors is concerned, potential abuse is not a sufficient reason to restrict if there exists the possibility to regulate and devise safeguards against abuse. Ultimately the First Section stated that most of the arguments of the Austrian government were aimed against gamete donation in general, like the arguments of eugenics and the right of the child to know its genetic origins, while sperm donation for in vivo fertilization is allowed.

Thus the First Section found that the prohibition at issue lacked a reasonable relationship of proportionality between the means employed and the aim sought to be realized. ${ }^{33}$ Although the court suggested throughout its opinion that Austria was entitled to a wide margin of appreciation in regulating assisted reproduction, its decision to oblige Austria to elect the least intrusive means and justify them with 'particularly persuasive' arguments signals its establishment of proportionality as the most appropriate standard for legislating in this context. ${ }^{34}$

\subsection{Consistent and Justified Policy Making in Areas of Contested Morality}

The focus on the standard of proportionality within a wide margin of appreciation amounts to an examination of the means-end rationality without interfering with the choice of ends. After the First Section judgement in S.H. and Others, the Austrian government could just as well abolish all gamete donation, as is the case in Italy, Lithuania and Turkey. In that case, the law would be consistent: it would be rationally related to the aim of preventing exploitation of donors and selection of children.

33) ECtHR First Section S.H. and Others v. Austria appl. No. 57813/00, 2010.

34) Supra note 28. 
The issue at stake here is whether it is preferable to demand that legislation on complex moral issues is consistent. The original demand for consistent policy making in S.H. and Others v. Austria could have had many unforeseen consequences. Intuitively, one would expect any policy to be consistent, especially one that is explicitly based on moral grounds. However, in the case of policies on medically assisted reproduction, the lawmakers want to ensure the welfare of the future child, cost-effectiveness, safety and equity in access, prevent exploitation of donors and surrogates and devise safeguards against abuse. Balancing these criteria may lead to complex compromises. Moreover, these complex compromises should fit in an entire legal system. Some laws may end up contradicting each other or some unforeseen loopholes may appear after enactment. Furthermore, medically assisted reproduction is rapidly evolving, both technically speaking and in public opinion, and it touches on sensitive private matters. A demand for some consistency may be a valid concern from a European perspective, but national legislation should be suited for the complexity of medically assisted reproduction in all its aspects.

For future reference, the First Section decision from the ECtHR effectively made nuanced policy making impossible based on the proportionality principle. Moreover, by focussing on the consistency of the law, the court has granted itself the power to question the effectiveness of legislation with only minor regard for the normative aim. However, people go to the court because they want to denounce a certain appreciation of the ECHR. Some moral intuitions that are deeply entrenched in some national legislation would not survive ethical scrutiny. The court should reprimand states for enacting legislation that is conform a national consensus, entrenched in national culture, identity and/or religion, but ethically flawed or inconsistent. On the other hand, how would that reflect on the EU's objective to respect national identities in private matters?

Take the French (and many other states') ban on assisted reproduction for same sex couples for example. A deontological justification for this policy would be based on the moral superiority of the traditional nuclear family. A child has a right to a mother and a father. However, given previous judgements of the ECtHR, a couple has a right to conceive a child and to make use of medically assisted reproduction to that end under Article 8 of the ECHR. ${ }^{35}$ Moreover, any difference in treatment should have objective and reasonable justification as required by article 14 of the ECHR. In S.H. and Others v. Austria, the court already refused to accept reasons of social acceptability such as unusual relationships (e.g., same sex parents) as a deontological argument. The French government would then have to produce other objective and reasonable grounds to restrict access to same sex couples. However, there is no ground for such a policy

35) E.g. ECtHR Dickson v. the United Kingdom appl. no. 44362/04, 2007. 
beyond the dogmatic and morally flawed position that it is unnatural for same sex couples to have children. ${ }^{36}$ The utilitarian argument that a child would not be reasonably well off with same sex parents has been disproved by recent research and more and more everyday examples.

\subsection{The Power of the Margin of Appreciation Doctrine}

The Grand Chamber reversed the judgement of the First Section based on the margin of appreciation: at the relevant time, the Austrian legislature did not exceed the margin afforded to it. ${ }^{37}$ The court observed that the Austrian parliament has not sufficiently reacted to the dynamic developments in science and society since the enactment of the law in 1992 . However, the government had several legitimate aims to interfere with the right to private and family life. Whether these aims were necessary in democratic societies or whether any alternative legislation would be more justified, is not up to the court to decide. State authorities are better equipped to answer this question. The court merely decides whether the prohibitions were justified at the time they were considered by the Austrian Constitutional Court. Because there is a wide margin of appreciation, the court judges this to be the case. Hence, the court develops a very minimalistic approach to review national legislation on medically assisted reproduction.

We supported the judgement of the First Section, but we disagreed with its reasoning. We disagree with the judgement of the Grand Chamber and we find the arguments to be weak. The Grand Chamber is correct in identifying Austria's normative aims as legitimate: who would not want to ensure the welfare of children, protect donors and prevent selective reproduction? However, a law that prohibits egg donation and sperm donation for the purpose of IVF has mainly different aims. Moreover, rather than to take these normative aims seriously, the current prohibition entails that the legislature gives up on the practice entirely. Such a law interferes with the basic right to private and family life. If an alternative is morally superior, there is something wrong with the current law. The First Section already found that alternatives and safeguards were readily available for all Austria's 'legitimate aims'. The Grand Chamber pays particular attention to the argument that egg donation interferes with the wish to maintain the basic principle of civil law - mater semper certa est. ${ }^{38}$ To add to the counterargument in the First Section judgement (i.e., there is nothing new about unusual relationships in modern families), Austrians still have the right to travel for egg donation, which means that the basic principle is already no longer maintained.

\footnotetext{
36) G. Pennings, "Evaluating the welfare of the child in same-sex families", Human Reproduction 26(7) (2011) 1609-1615.

37) ECtHR Grand Chamber S.H. and Others v. Austria appl. No. 57813/00, 2011.

38) Ibid.
} 
The court allows a wide margin of appreciation because legislation on medically assisted reproduction is a matter of morality. An a fortiori argument advanced by the Grand Chamber for allowing the wide margin is that there is no European consensus. However, consensus has no moral value: people can agree on immoral views. These views should be subject to ethical scrutiny, but the court treats them as the product of it. The court also states that people always have the option of going abroad. This can be seen as a pragmatic reason for a wide margin of appreciation. However, as the dissenting opinion of Judges Tulkens, Hirvelä, Lazarova Trajkovska and Tsotsoria also states: this argument does not address the real question, that of interference with the applicants' private life as a result of the absolute prohibition in Austria. ${ }^{39}$ The judgement of the Grand Chamber is falls short because it uses the margin of appreciation as a pragmatic substitute for a well thought-out approach to the problem of proper scope of review in areas of contested morality.

\section{Conclusion}

Legal diversity in legislation on medically assisted reproduction and growing flows of patients crossing borders to evade restrictive laws constitute a threat to the protection of national identities within the EU. The individual state could end CBRC for law evasion by enacting extraterritorial legislation. This is only justified if there is an indisputable moral wrong. What constitutes such a wrong can only be defined in legal terms by referring to human rights. EU laws and courts, specifically the ECHR and ECtHR should remove the need for extraterritorial protection of moral interests. In areas of contested morality the ECHR is interpreted by different Member States in diametrically opposed ways, which indicates the need for some form of third party oversight. However, as the ECtHR allows a wide margin of appreciation in matters of private life, such oversight is limited to demands for proportionality, consistency and proper justification. In S.H. and Others v. Austria, the First Section focussed mainly on the means-end rationality behind the law and little on the moral end. The Grand Chamber used the margin of appreciation to formulate a minimalistic approach to review national legislation. In the future, the court should live up to its role as third party overseer on respect for human rights in Europe. To that end, the court should focus on the normative aim of laws on medically assisted reproduction and narrow the margin of appreciation in this matter of private life when there is arbitrary interference with the basic right to family life.

The core tension at EU level in the case of CBRC for law evasion is the conflicting interest between unifying measures at EU level and the right to national

39) Dissenting opinion of Judges Tulkens, Hirvelä, Lazarova Trajkovska and Tsotsoria in ECtHR Grand Chamber S.H. and Others v. Austria appl. No. 57813/00, 2011. 
identity at national levels. In the EU, free movement of persons and the margin of appreciation doctrine adopted by the ECtHR, has led to a situation where any treatment that is legal in one Member State is available to all Europeans, regardless of the moral convictions of their state of affiliation. In the end, this may be a good situation for the cross-border patient, but less so for states with a clear moral position. 